\title{
Perspektiven sind gut - aber wohin läuft der Hase?
}

\section{Werner Bauer}

Dr. med., Präsident des Schweizerischen Instituts für ärztliche Weiter- und Fortbildung SIWF

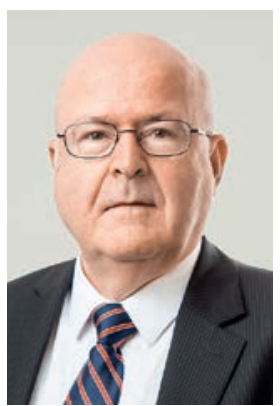

Diese Nummer der Schweizerischen Ärztezeitung enthält den Bericht über das fünfte MedEd Symposium des Schweizerischen Instituts für ärztliche Weiter- und Fortbildung. In Vorträgen, Workshops und im Rahmen eines Podiumsgesprächs wurden Perspektiven der ärztlichen Bildung bearbeitet.

Das Wort Bildung wurde mit Absicht gewählt, betont es doch den dringenden Wunsch, dass Ärzte nicht nur aus-, weiter- und fortgebildet sein müssen, sondern dass ihr Bildungsspektrum auch über das rein Fachliche hinausreichen sollte. Bewusst definiert deshalb der vielfach übernommene kanadische Lernzielkatalog CanMEDS unter den Rollen des Arztes nicht nur den ärztlichen Experten oder den Gesundheitsförderer, sondern ebenso den Gelehrten (scholar) und den Kommunikator. Auch der legendäre William Osler betonte, "physicians need culture», und erkannte in der fundierten und bewusst gepflegten Allgemeinbildung von der Literatur bis $\mathrm{zu}$ den bildenden Künsten ein Erfordernis und auch eine Hilfe bei der Bewältigung beruflicher Anforderungen. Der Hase müsste also in Richtung einer vertieften Bildung laufen. Wir aber müssen zur Kenntnis nehmen, dass es in der Realität des Gesundheitswesens einen besonderen, nicht immer leistbaren Energieaufwand braucht, um neben den fachlichen auch die allgemeinen Lernziele genügend zu vermitteln.

Einige weitere Berichtspunkte verdienen einen Kommentar, zum Beispiel das «routinemässige Vorgeplänkel mit dem Direktor des Bundesamtes für Gesundheit» bei der Eröffnung der Tagung und «die freundliche Post, die das SIWF gelegentlich vom BAG erhält». Bei dieser freundlichen Post handelt es sich um die 45 Briefe aus dem Eidgenössischen Departement des Inneren, in welchen alle Facharzt-Weiterbildungsgänge wieder für sieben Jahre anerkannt werden. Voraussetzung dafür, im Mandat der Eidgenossenschaft die Facharzttitel zu erteilen, ist gemäss Gesetz eine periodische Akkreditierung, die nun dieses Jahr nach einer aufwendigen Evaluation den Fachgesellschaften und dem SIWF eine hohe Qualität bescheinigt hat. So weit, so gut, und so freuen wir uns denn über die anerkennende Post. Doch der BAG-Hase rennt nicht nur heiter hinter knackigen $\mathrm{Zu}$ sammenarbeitsrüben her, er schlägt gelegentlich auch schwer nachvollziehbare Haken. Es geht in diesem Zu- sammenhang nicht um brisante Tariffragen, sondern um eine grundsätzliche Denkweise, die notorisch zu werden scheint und eine partnerschaftliche Zusammenarbeit erschwert, wobei sich diese leidige Beobachtung nicht auf das BAG oder auf die eidgenössische Administration beschränkt. Wären nämlich bestimmte Verwaltungsabteilungen lebende Organismen und würde man bei ihnen eine Genomanalyse durchführen, so stiesse man mit Sicherheit auf zwei dominante Gene: eines, welches ein tiefes Misstrauen gegenüber selbstverantwortlichen Aktivitäten des Ärztestandes triggert, und eines, welches die Synthese von neuen Regulierungen und strikteren Kontrollmechanismen stimuliert. Und so hoppelt denn der Paragraphen- und Verordnungshase immer weiter und weiter ...

Ein Thema, das im Bericht auch angesprochen wird, ist die Feststellung des irischen Gastreferenten, dass die Weiterbildung im 21. Jahrhundert eine Aktualisierung braucht und nicht in der Methodik des 19. Jahrhunderts stecken bleiben darf. Als Chirurg macht der Referent auf die Probleme eines effizienten Trainings angesichts der heute geltenden Arbeitszeitbeschränkung und der tendenziell nicht mehr genügenden Anzahl Patienten aufmerksam. Eine Binsenwahrheit, möchte man meinen, aber auch auf dieser Wiese läuft der Hase nicht zielstrebig zum nächsten Löwenzahnbüschel, sondern er hat Mühe, dieses zu finden. Es gilt, effizientere Methoden der Kompetenzvermittlung zu entwickeln und zu nutzen (Simulation, blended learning), die administrativen Belastungen endlich zu reduzieren und Dienstleistung, Weiterbildungsbedarf und Arbeitszeit zu harmonisieren.

Eine letzte Feststellung gilt der Kommunikation: Obwohl ihre zentrale Bedeutung stets betont wird, beruhen viele Probleme am Arbeitsplatz und im Verhältnis zwischen Patienten und Ärzten auf ungenügender, unsensibler oder ungeeigneter Kommunikation. Der Referent von der Mayo-Klinik wies darauf hin, wie wichtig neben dem Inhalt die Art und Weise ist, mit der eine Botschaft übermittelt wird, sei dies bei einer Präsentation oder im Alltag des Lehrens oder des Gesprächs mit Patienten. Zu oft rennt ein gehetzter Kommunikationshase unbeachtet umher. Fazit: Die Perspektiven stimmen, aber das Kraut für umherirrende Hasen muss erst noch wachsen. 